تعيين سهم نسبى زيرحوضهها در توليد رسوب بهوسيله دادهاى بذيرفتارى مغناطيسى

\author{
كيوان صيدىنوره'، شمساله ايوبى "* و كاظم نصرتى
}

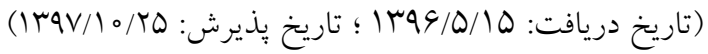

جكيده

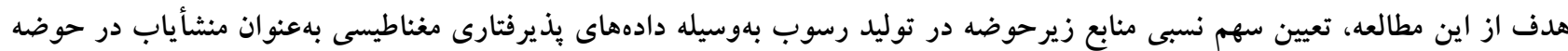

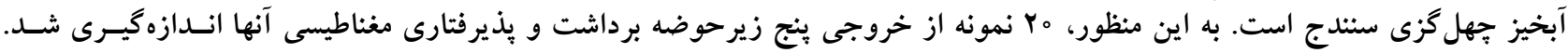

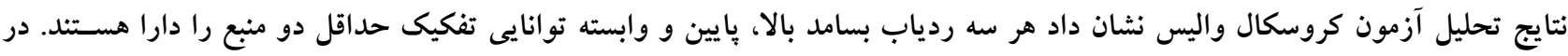

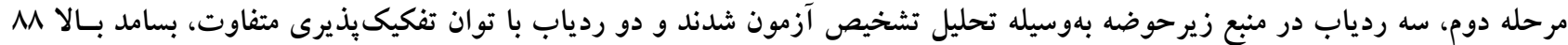

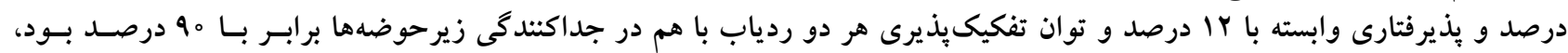

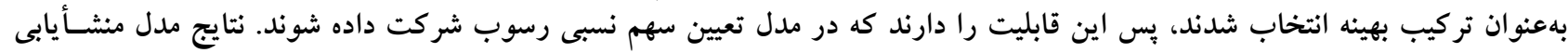

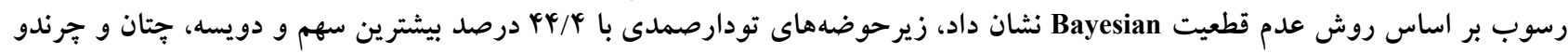

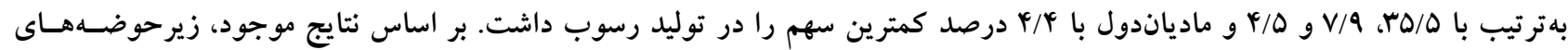

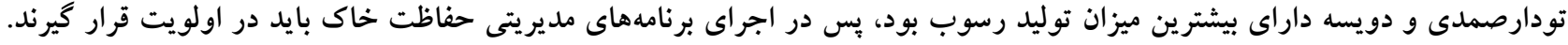

وازههاى كليدى: منشأيابى رسوب، يذيرفتارى مغناطيسى، حوضه آبخيز جهل گزى، مدل عدمقطعيت Bayesian

1. كروه علوم و مهندسى خاك، دانشكده كشاورزى، دانشكاه صنغتى اصغهان

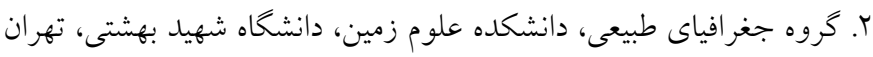

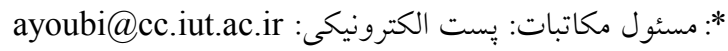




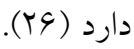

مقدمه

بهمنظور كتترل رسوب و اجراى برنامههـاى حفاظـت خـاى

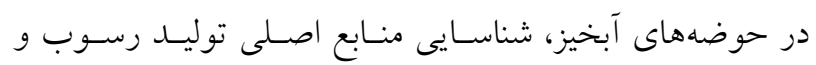
منـاطق فرسـايشيـــير امسرى ضـرورى اسـت، زيــرا برخسى از استراتزىهاى حفاظـت خـاك بايــــ روى منـابع اصـلى متمركـز شوند، در همين راستا مطالعات منشأيابى رسوب بهعنوان روشى كارامد، سريع و كمهزينه مىتواند استفاده شود. روش منشأيابى رسوب (Sediment fingerprinting)، تعيين سهم نسبى هريك از منابع رسـوب در توليـا رسـوب براسـاس

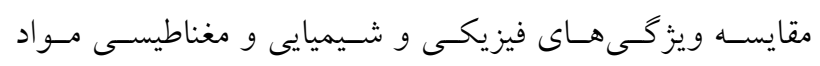

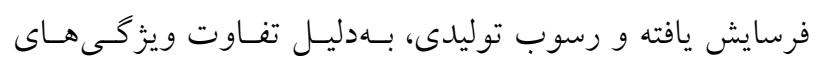
رسـوبات بـهدسـت آمــده از مراتـع و زمسينهـاى كشـاورزى و رسوبات كناره رودخانه است (TQ). براى فرايند مقايسه نياز به يكسرى ويز كىها و رديابهايى است. بهطور كلى روش منشأيابى شامل دو مرحله است؛ مرحله

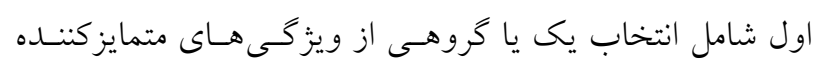

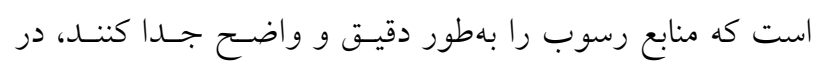
مرحله دوم با روشهاى آمارى، تركيبى بهينه كه قادر به تفكيـك دقيق منابع رسوب باشد از تركيب اوليه استخراج مىشود.

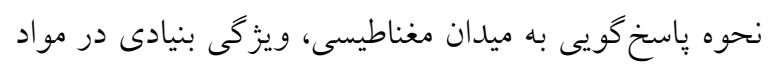

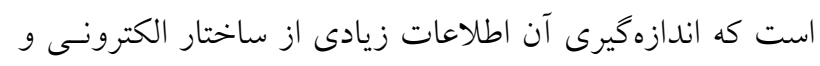
وجود حالتهاى مغناطيسى منظم در ماده را بهدسـت مسىدهـد.

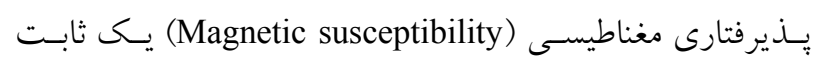
بدون بعد است كه نشانكر درجه مغناطش يك ماده در ياسخ آن ماده به ميدان مغناطيسى است. بكون.

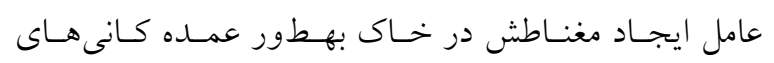
مخنتايت و مخهمايت هستند درحالى كه كانىهاى آهندار ديخر غيرمغناطيس و حتسى برخهى تركيـات موجــود در خـاك نظيـر

كربنات ها دار اي يذيرفتارى مغناطيسى منفى هستند (بr). بهطور كلى سه نوع رفتار مغناطيسى وجــود دارد كـه شـامل ديامغنــاطيس، يار امغنــاطيس و فرومغنــاطيس مـى شــود (YV)

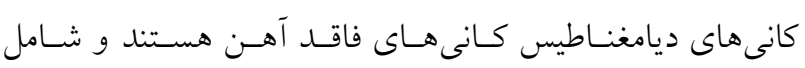

متأسـفانه تغيــرات شـديد محسيط زيسـت در جنـــ دهـه اخيـر

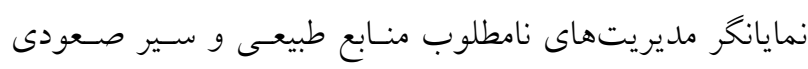
نايايدارى اكوسيستمها در كشور است. دليل ايسن امـر بــه تغييـر نآَكاهانه و غيرعلمى كاربرى اراضى مرتعى و جنشلى و استفاده از سيستمهاى مختلف خاكورزى بدون شناخت كـافى از محسيط خاك، طى ساليان متمادى نسبت داده شده است. بر اساس نتايج

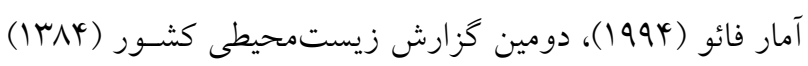

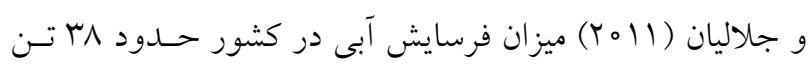
در هكتار در سال براورد شده است كه مب تا هب برابر حد قابـل

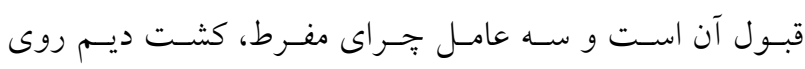
شيبهاى تند و جنغلتراشى را از علـل تخريـب خــاى اعـلام

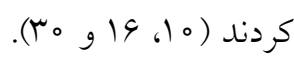
فرسايش خاك بهعنوان يكى معضل زيستمحيطى شـناخته مى شود و برّوهشهاى انجامشده در ايران نشان مىدهـــ شـــت فرسايش خاى در ايران زياد بوده است و هرساله خسارتهـاى جبراننايذيرى به كشور وارد مى كند كه از جمله مىتوان بـهـ هـر شدن مخازن سدها، وقوع سيلابهــا و روانـابهـاى دهـههـاى اخير، آلودكى آب و خسارت به تأسيسات آبيارى و از بين رفتن

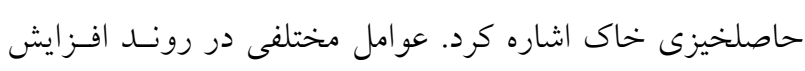
فرسايش و رسوب خاى در كشور دخالت دارنـــ كـهـ از جملـه. اين عوامل مىتوان به تبديل مراتع به ديمزارهـا، جنخـلتراشـى، ديم كارى در زمينهاى شيبدار، عمليـات نادرسـت كشـاورزى، آتشسوزى جنگل ها و مراتع و عوامل متعدد ديخـــ اشـاره كـرد

بيشترين مساحت در معرض خطـر فرسـايش در جهـان بـه قاره آسيا با هم ميليون هكتار و يس از آن مربوط به قاره آفريقـا،

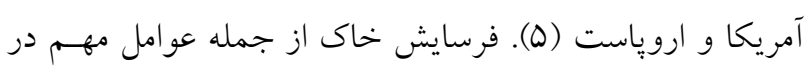
تخريب زمينهاى خشك و نيمه خشك ايران است. با توجـه بـه اينكه فرسايش خاى در اثر تخريب ويزگى هـاى فيزيكى خـاى تشديد مىشود، نياز به بررسى تأثير شاخصهاى كيفيـت خـاى بر فرسايشيذيرى خاك در كاربردهــاى مختلـف زمسين وجــود 


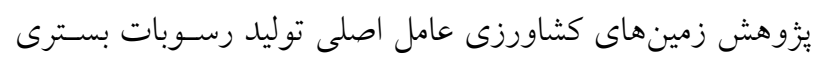

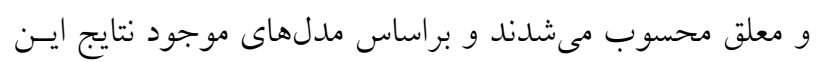

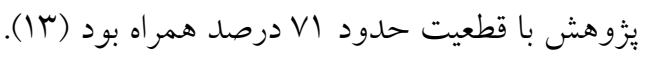

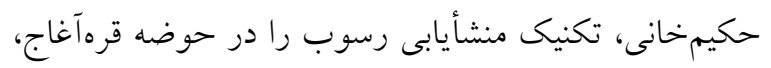

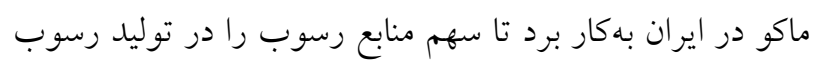

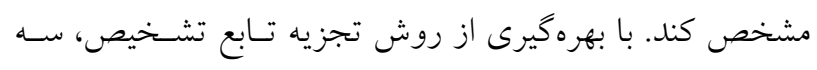

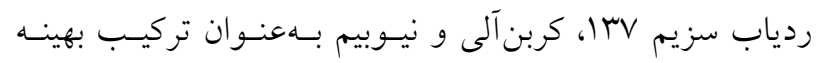

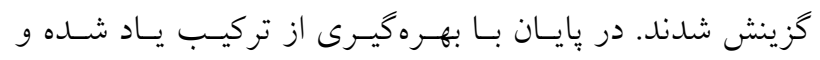

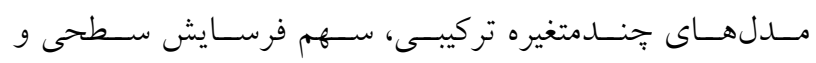

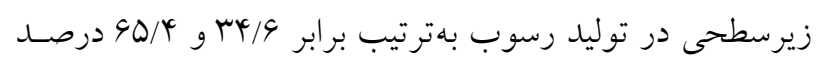

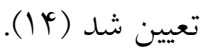

در مطالعهاى نيز بـه منشـأيابى رسـوب بـ بـا استفاده از دادههـاى

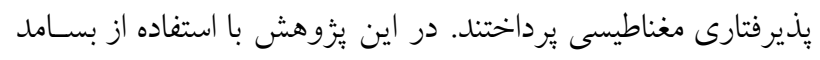

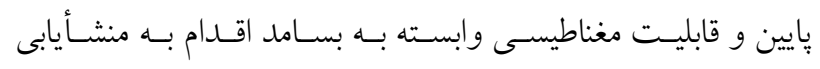

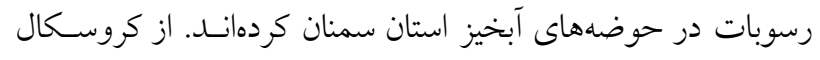

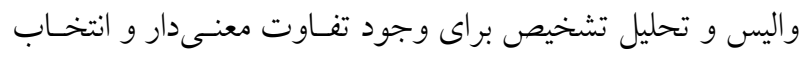

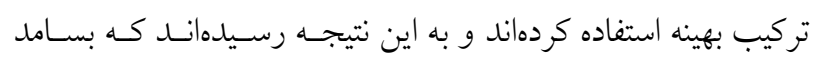

وابسته قابليت خوبى در تفكيك منابع رسوب دارد (1) (1).

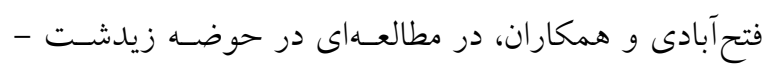

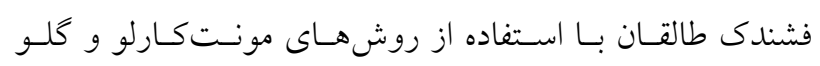

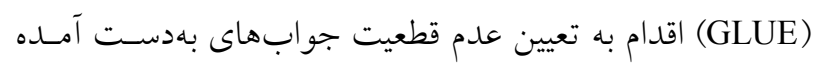

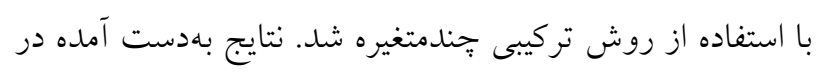

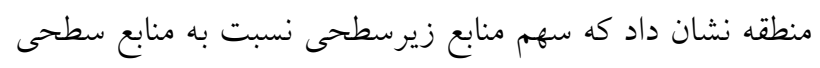

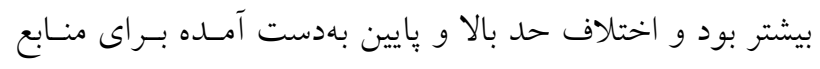

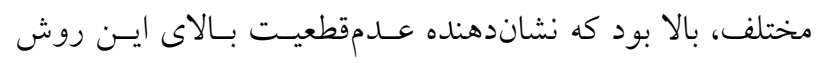

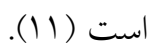
از اينرو مطالعات منشأيابى رسوب بلهنوان روشى كارامــ،

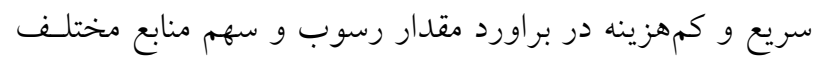

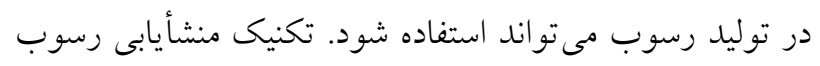

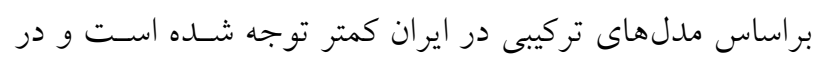

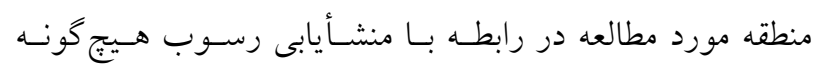

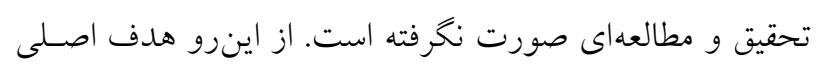

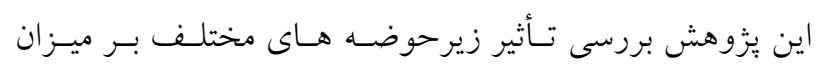

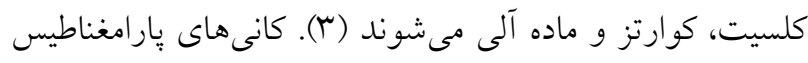

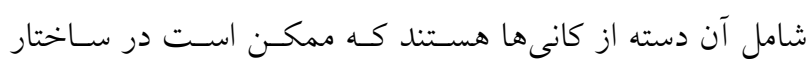

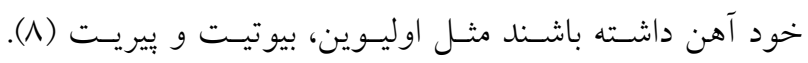

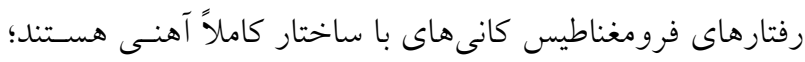

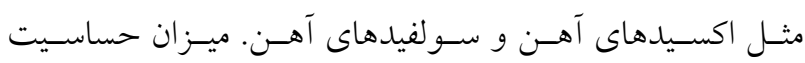

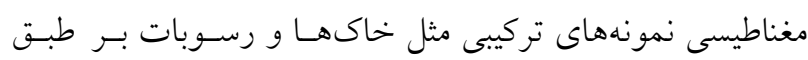

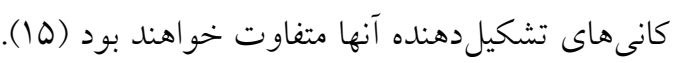

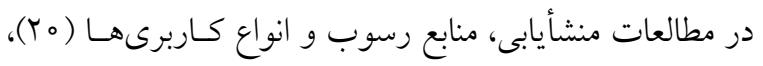
فرسايش سطحى و زيرسطحى (YY)، و منـابع مكـانى از جملـه

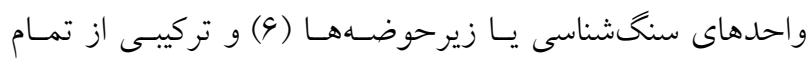

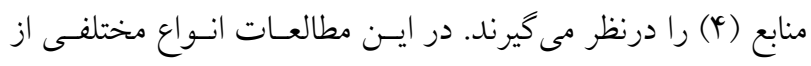

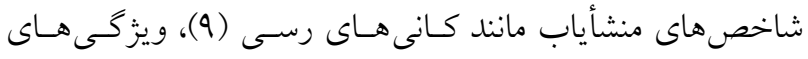

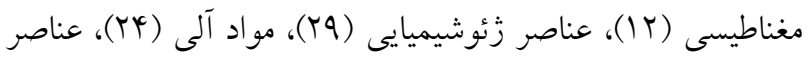
راديو اكتيو (4) رنخ خاك و اندازه ذرات خاك (Y) براى تفكيكى منابع رسوب مورد استفاده قرار مى گيرند.

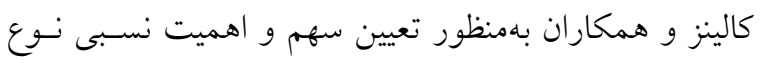
منابع رسوب از جمله فرسايشهاى سطحى و زيرسطحى (مانند

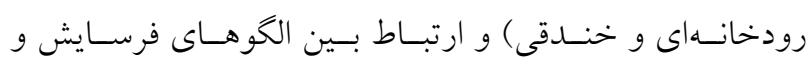

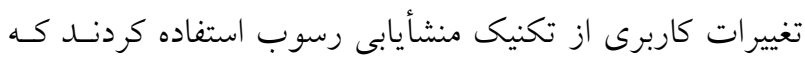
در همه مـوارد فرسـايش زيرسـطحى سهم بيشـترى در توليــ

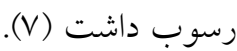
نصرتى و همكاران در مطالعهاى بـه منشـأيابى رسـوبات از دان

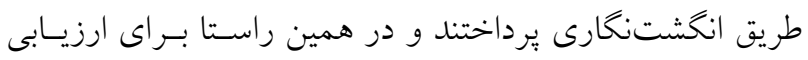

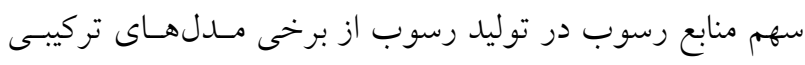

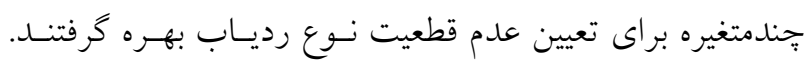

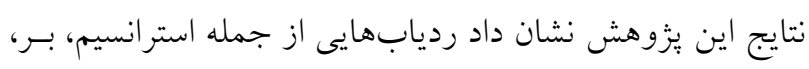

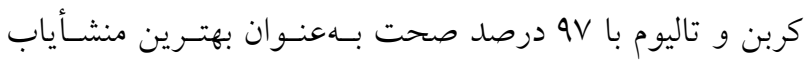

رسوب در منطقه بودند (Y) (Y).

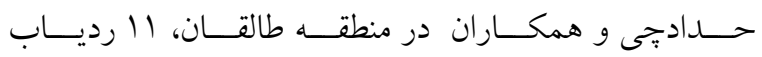

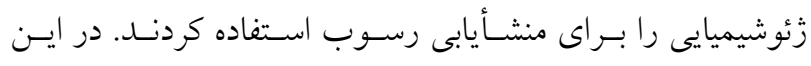

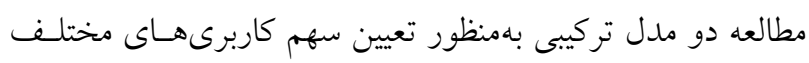

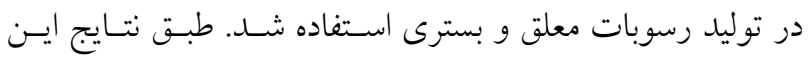



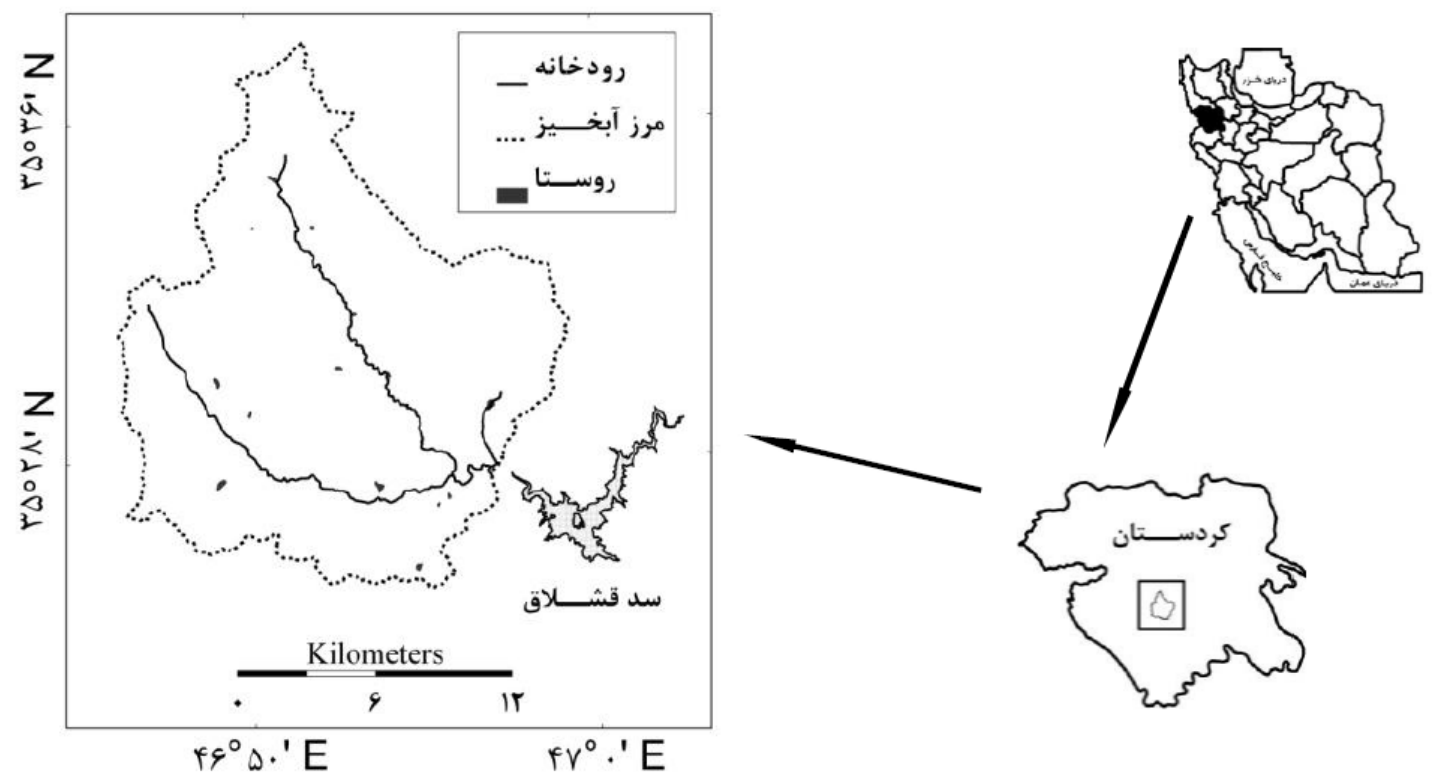

شكل ا. موقعيت جغرافيايى منطقه مورد مطالعه در استان كردستان

رودخانه دائمى است كه از شمال و غرب سرجشمه مى گيرند و به جنوبشرقى آن ختم مىشوند. متوسط بارش سـاليانه منطقـه

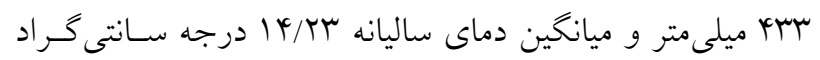

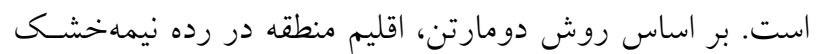

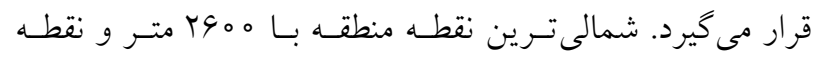
خروجسى حوضسه 1900 متسر ارتفـاع از سـطح دريـا بـهنترتيـبـ بلندترين و يست ترين نقاط ارتفاعى منطقه هستند. منطقه از نظر

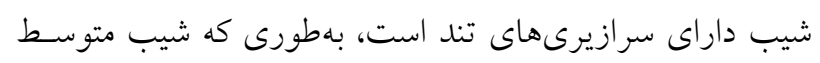

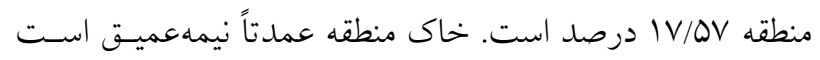
با بافت غالب شنى لومى و داراى گروههــاى هيـدرولوزيكى B و C، رزيم رطوبتى زريـك و رزيــم حرارتسى مزيـك اسـت و در زيرردههاى بزرگ خاك در گروه انتىسول قرار مى گيرد. حوضه از سنخهاى آندزيتى، شيلى و آهكى تشـكيل شــده و از لحـاظ زئومورفولوزى، بيشتر سطح منطقه كوهستانى است (1).

نمونهبردارى و آناليزهاى آزمايشخاهى

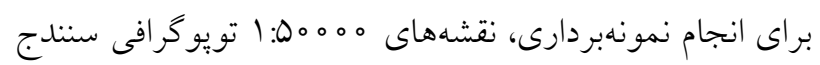
و باينجوب كه از سازمان جغرافيايى نيروهاى مسلح تهيـه شــه

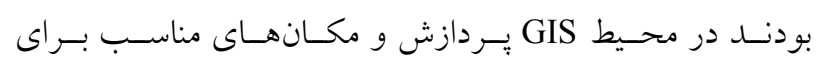

فرسايش و توليد رسوب به روش انخشتنگارى در منطقه مورد مطالعه است تا با شناخت مناطق حساس و يرخطـر، روشهـاى مناسب مبارزه با فرسايش در آنها اسـتفاده شـود. در ايسن راسـا اهداف زير تعريف شده است: - تعيين ميزان توليد رسوب (سـهم نسـبى منسابع رسـوب) در زيرحوضهها.

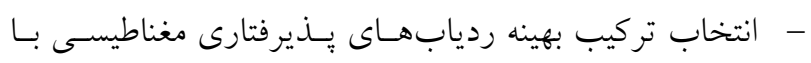
توجه به اندازه گيرى شاخصها و تجزيه و تحليل آمارى.

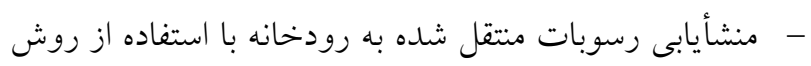
انخشت نشارى و تعيين عدمقطعيت آنها با مدل Bayesian.

\section{مواد و روش مها} توصيف منطقه مورد مطالعه در اين بزوهش حوضه آبخيز جهال گزى سد قشاق، با مساحت

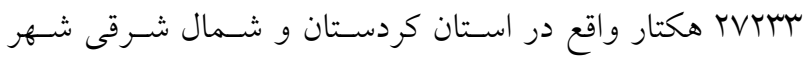

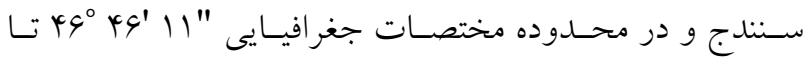
"ه عرض شمالى، مورد مطالعه قرار گرفته است (شكل (1). حوضه از نظر منابع آبسى داراى تعـداد زيـادى جشــمه و دو 


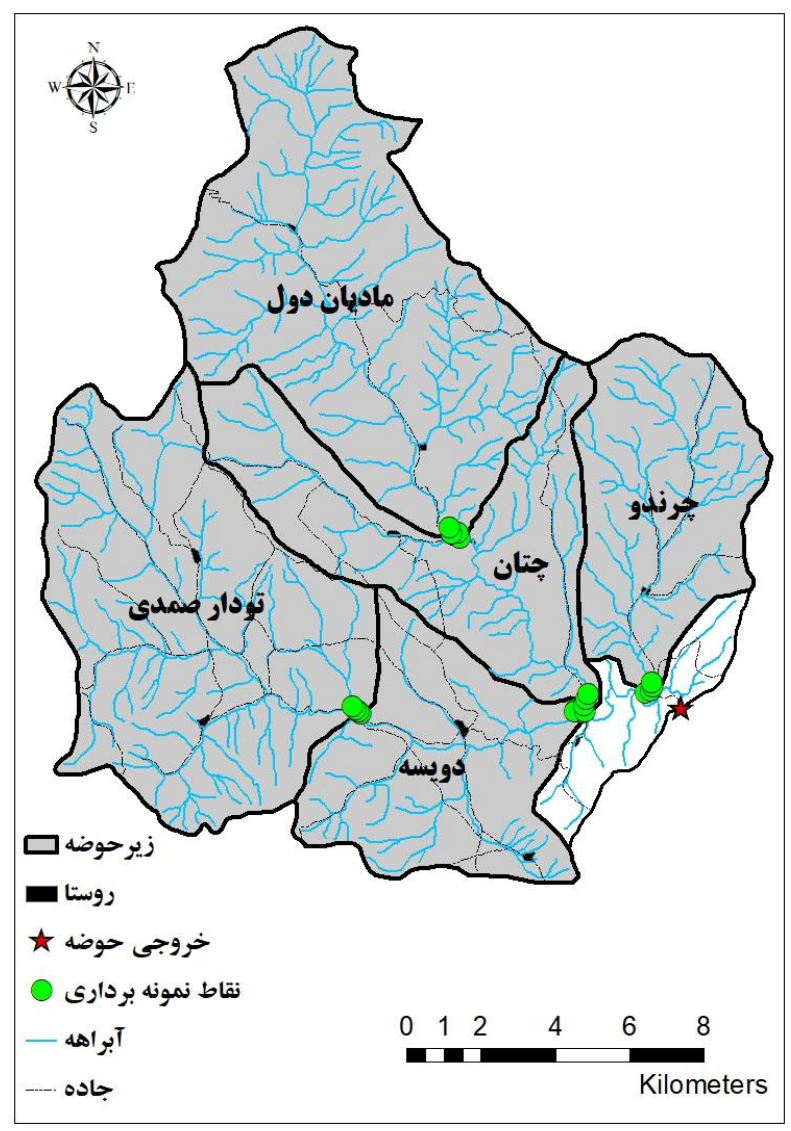

شكل r. نقشه آبراهه و نقاط نمونهبردارى منطقه

در خروجى حوضه و همجنــين نقـاط نمونسهبــدارى رسـوبات كفبستر هر زيرحوضه را نشان مىدهد. نمونهها در هواى آزاد خشـك شـد. سـبس كوبيـده شـده و

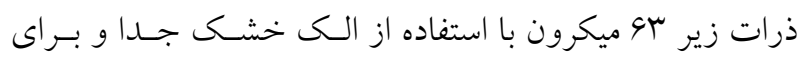
آناليز در مرحله بعد آماده شد. يذيرفتارى مغناطيسى در بسـامد بـايين (X X

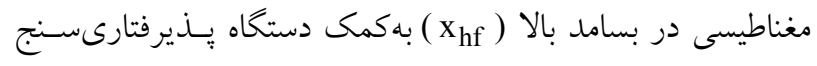
مدل Bartington MS2 Dual Frequency Meter اندازهگيرى شد و يذيرفتارى وابسته به بسامد از رابطه زير محاسبه شد.

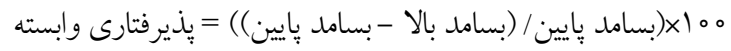

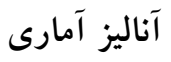

براى انتخاب تركيب بهينه رديابهـايى كـهـ تـوان جداسـازى و
نمونهبردارى مشخص شدند. نمونهبردارى از منطقه با توجـه بــه شرايط تويوگر افيك و مساحت زياد آن سخت و زمانبـر بـود و رسوبات تازه تهنشين شده در خروجى كف آبراهههاى هر كدام از زيرحوضهها به طول سه كيلومتر از خروجى حوضه با جهـار تكرار برداشت شدند. فاصله هر نمونه با نمونه بعـدى مUا متـر بود. مب نمونه از محل خروجى بنج زيرحوضه برداشت شـدند.

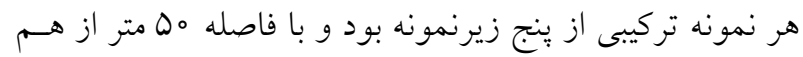
برداشت شدند تا نمونههاى رسـوب نماينـده واقعى از جامعسه باشند. نمونهبردارى از رسوبات جديد صورت گرفت. براى هـر نمونهبردارى از رواناب در طول هر هشت رخــداد مهـم بارشىى كه در سال \&4 اتفاق افتاد، هر ها دقيقه يكبار از رسوبات معلق واقع در خروجى حوضه نمونهبردارى شد و در يايان هر رخداد بارشى، نمونهها با هم تركيب و سيس صاف شدند. در مجمـوع هشت نمونه برداشت شد. شكل (Y) محل نمونهبردارى روانـاب 


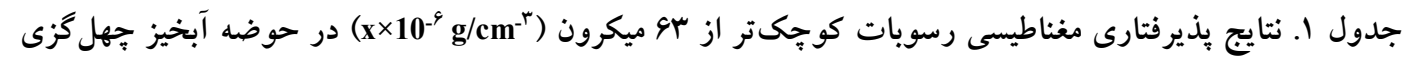

\begin{tabular}{|c|c|c|c|c|c|c|c|}
\hline \multicolumn{8}{|c|}{ يذيرفتارى مغناطيسى نمونههاى منابع رسوب } \\
\hline 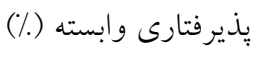 & بسامد بالا & بسامد يايين & زير حوضه & يذيرفتارى وابسته (٪) & بسامد بالا & بسامد يايين & زيرحوضه \\
\hline ऍ/^९ & TG/NT & TV/A。 & تودار صمدى & $\varphi / 4 \circ$ & $\mathrm{VG/D \Lambda}$ & $\wedge \circ / 1 \circ$ & مادياندول \\
\hline $4 / 14$ & $M \mid / T$ & $r / 90$ & ميانخين & $\varphi / \mu 1$ & $V I / \Lambda_{0}$ & $V Q / \circ r$ & مادياندول \\
\hline ०/AT & $\Delta / V Y$ & $9 / \pi 1$ & انحراف معيار & $4 / 10$ & $\triangle \Delta / \wedge \triangleright$ & $\Delta \wedge / T \Lambda$ & 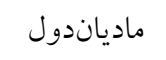 \\
\hline $9 / 09$ & $\Lambda \mu / \varphi \Lambda$ & $M N / q_{0}$ & جرندو & F/MT & D & $\Delta \Delta / \Lambda \mu$ & مادياندول \\
\hline$\Delta / \wedge \Delta$ & $\mathrm{Vq} / 9 \mathrm{r}$ & $\Lambda Y / \Delta \wedge$ & جرندو & r/Mt & $q 4 / \mu q$ & $9 V / M 1$ & ميانخين \\
\hline $9 / 1 V$ & $W / T Q$ & תr/N & 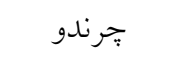 &.$/ 14$ & $11 / 0 r$ & $1 Y / 09$ & انحر اف معيار \\
\hline $9 / 44$ & $\vee q / \Lambda \Lambda$ & $\Lambda Q / \mu \wedge$ & جرندو & $\Delta / M T$ & TG/Tr & TV/V。 & دويسه \\
\hline $9 / 14$ & $10 / 04$ & $\Lambda \Delta / r q$ & ميانخين & $Y / M Y$ & $Y Y / Y A$ & $T Q / 9 \circ$ & دويسه \\
\hline$O / Y Y$ & $r / Q V$ & $r / N$ & انحراف معيار & Q/or & $T Y / D Q$ & $r Q / \wedge Q$ & دويسه \\
\hline $0 / 01$ & $\mu q / \mu \circ$ & 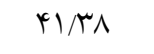 & جتان & $r / \pi q$ & $T Y / q_{0}$ & $r \varphi / 00$ & دويسه \\
\hline$Y / Q V$ & yl/r。 & $F r / r \Lambda$ & جتان & $Y / V V$ & $T Q / \circ Y^{C}$ & TG/T。 & ميانگين \\
\hline $4 / 90$ & MT/N & $49 / 00$ & جتان & $\circ / \uparrow \wedge$ & $\circ / \Lambda 1$ &.$/ 90$ & انحراف معيار \\
\hline$\varphi / \Delta 0$ & $Y \wedge / D_{\circ}$ & $\Delta \circ / \Lambda \circ$ & جتان & $Y / Y \Lambda$ & ( & re/vo & تودار صمدى \\
\hline$Y / V V$ & 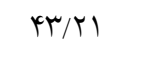 & $\varphi \Delta / \mu_{\varphi}$ & ميانخين & $0 / 19$ & $r V / \circ \Lambda$ & $r q / 1 \circ$ & تودار صمدى \\
\hline$O / T Y$ & $r / 9 V$ & $4 / 0 q$ & انحراف معيار & س & $r Q / Q_{0}$ & rG/N。 & تودار صمدى \\
\hline
\end{tabular}

مغناطيسى رسـوبات در دو بسـامد بـالا و يـايين و يـــيرفتارى وابسته به بسامد (درصد) بهعنوان ردياب سوم آورده شده اسـت (جدول (1) ( ) (ج)

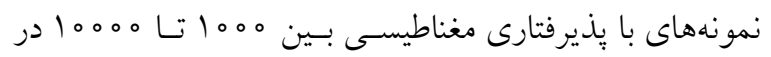
طيف كانىهاى فرومغناطيس قرار دارند كه سرشار از اكسيد آهـن هستند و اعداد •ه تا ه م إ در طيف كانىهاى يار امغنـاطس قـرار

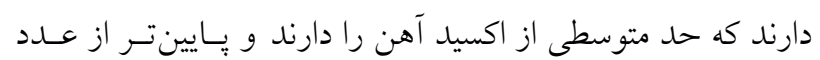
هD نمونهاى رسوب مربوط به كانىهاى ديامغناطيس هستند كـه

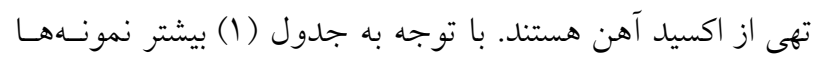
داراى كانى هاى بارامغناطيس و ديامغناطيس هستند. براساس نتايج جدول (Y) رديابهاى بسامد بـالا و بـايين و يذيرفتارى وابسته در اندازه ذرات يايين تر از سوه/ه ميلى متر در منبع زيرحوضه داراى قابليت جداكنندكى خوبى هستند. در ايسن

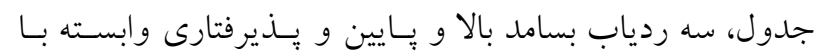
اطمينان ه9 درصد در منبـع زيرحوضـه داراى تفـاوت معنسى دار
تفكيـك منــابع رسـوب را داشـته باشــند، يـك روش آمـارى دومرحلهاى بهكـار گرفتـه شــ (YT). در مرحلـه اول از آزمـون

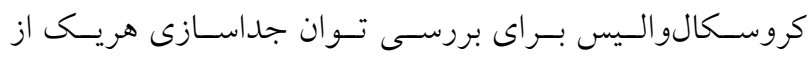

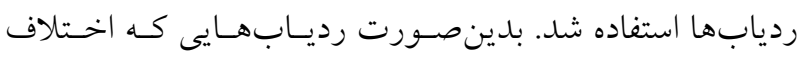
ميانخين كمتر از هـ/ داشتند، وارد مرحله دوم شدند. در مرحله دوم بهمنظور انتخاب تركيب بهينه از زيرمجموعه رديابهـا كـه بهنوان ويزز گى بالقوه در مرحله اول انتخـاب شـــند، از تحليـل

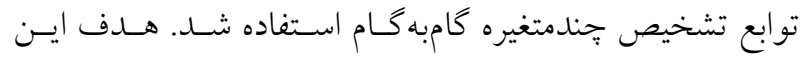
تحليل به حداكثر رساندن تفكيك بين منابع با به حداقل رساندن

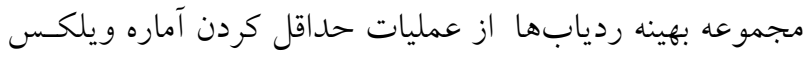
لامبدا (Wilks Lambda) اسـتفاده شـــ. بـهنظــور تحليـلهــاى آمارى از نرمافزار 19 SPSS استفاده شد (Y^).

نتايج و بحث

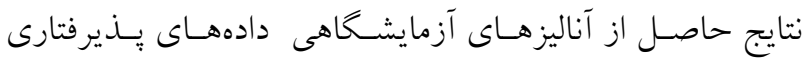


جدول r. نتايج آزمون كروسكال واليس در بررسى توان رديابهاى مغناطيسى در جداسازى منابع رسوب در منبع زيرحوضه

\begin{tabular}{|c|c|c|c|}
\hline سطح معنى دارى & آماره H & اندازه ذرات رسوب (ميلى متر) & ردياب \\
\hline $0 / 001$ & $|\Lambda / \circ V|$ & . /.9 $>$ & بسامد بالا \\
\hline $0 / 001$ & $|N / \circ V|$ & $0 / 0 q \mu>$ & بسامد بِايين \\
\hline.$/ 010$ & $\mid r / 0 \circ$ & $. / 09 \mu>$ & 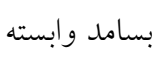 \\
\hline
\end{tabular}

جدول r. نتايج تحليل تشخيص در تعيين تركيب بهينه رديابها در منبع زيرحوضه

\begin{tabular}{|c|c|c|c|c|c|c|}
\hline طبقهبندى صحيح منابع (.) & سطح معنى دارى & $\mathrm{F}$ & ويلكس لاندا & اندازه ذرات & حساسيت & روش تحليل تشخيص \\
\hline$\Lambda \Lambda$ & $\circ / 000$ & $\Delta V / \circ \circ \circ$ & $0 / 091$ & $<0 / 09 \mu$ & بسامد بالا & \multirow{2}{*}{ كامبه كام } \\
\hline ir & $\circ / \circ \circ \circ$ & $r y / \circ r Y$ & $\circ / 0 Y_{0}$ & $<0 / 09 \mu$ & يذيرفتارى وابسته & \\
\hline
\end{tabular}

شكل تفكيك منـابع رسـوب در واحسدهاى زيرحوضـه توسـط توابع يك و دو بهدرستى انجام گرفته است.

سهم واحدهاى زيرحوضه در توليد رسوب با توجه بـه اينكـه از خروجسى حوضـه هشـت نمونسه رسـوبـ برداشت شده بود مدل عدمقطعيت Bayesian هشـت بـار بـراى تكتى نمونه رسوبات بهوسيله برنامه Matlab اجرا شــ و بـار ديخر مجموع آنها يكجا استفاده شدند و سهم نسـبى رسـوبات در هر بنج زيرحوضه در صدكهاى ه، مها و ه 9 بهدست آمدند، كه در جدول (ه) صدى ينجاه بيانخر ميانه سهم نسبى هـر منبـع در توليد رسوب و صدى ه و هو بيانخر عدمقطعيت موجود در

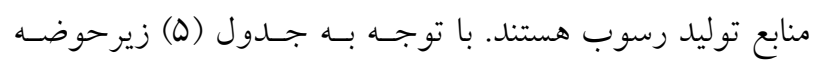

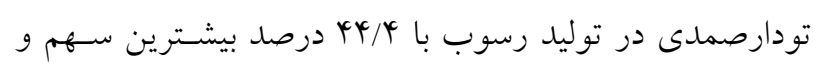
زيرحوضه مادياندول با \&/4 درصد كمتـرين سـهم را در توليـد رسوب داشت. در شكل (†) سهم نسبى توليد رسوب بهصورت مورت تركيبى با استفاده از مدل عدمقطعيت Bayesian نشان داده شــه

\section{نتيجه كيرى}

نتايج حاصل از اين يـرّوهش نشـان دهنـــه اهميـت بـــيرفتارى مغناطيسى رسوبات در تفكيك بذيرى منابع توليد رسوب اسـت.
هستند. به اين ترتيب، رديابهاى ذكر شده در منبـع زيرحوضـه قابليت تفكيك كنند كى منابع را دارند. بعد از آزمون H نياز هست تا تركيب بهينه رديابها مشخص سيع شود. براين اساس، سه ردياب در منبع زيرحوضه بهوسيله تحليـل

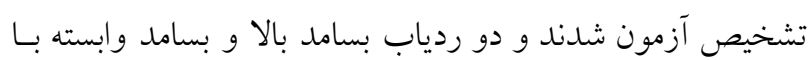
قدرت جداكنندگى متفاوت (بسامد بالا برابر M د درصـد و بسـامد

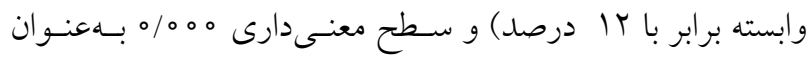
تركيــب بهينــه تشــخيص داده شـــند (جـــول س) و قــدرت جداكنندگى هر دو ردياب بـا هــم در جداكنتـدگى زيرحوضـههـا برابر با هو درصد بود. بـهـ ايسن ترتيـب ايسن دو رديـاب در منبـع زيرحوضه اين قابليت را دارنـــ كـه در مـــل تعيسين سـهم نسـبى

$$
\text { رسوب شركت داده شوند. }
$$

جدول (أ) درصد طبقهبندى صحيح در هـر گـروه و تعـداد نمونههاى درست طبقهبندى شده را نشان مىدهد. بـا توجسه بـــ اين جدول نمونهها در زيرحوضه ه9 درصد صحيح برداشـت و طبقهبندى شدهاند. طبقهبندى صحيح بهطـور كلى برابـر بـا 90 درصد است. قسمت دوم جدول نيز نتايج ارزيابى متقابل تحليل تشخيص را نشان مىدهد. در اين قسـمت طبقهبنـدى صـحيح برابر با هو درصد است. براى بررسى بيشتر تـوان توابـع تحليسل

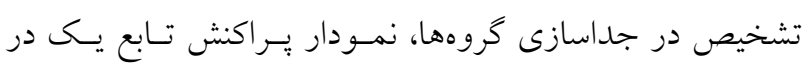
مقابل تابع دو در شكل (r) نشان داده شده است. باتوجه به ايسن 
جدول f. درصد طبقهبندى صحيح نمونها در واحدهاى زيرحوضه

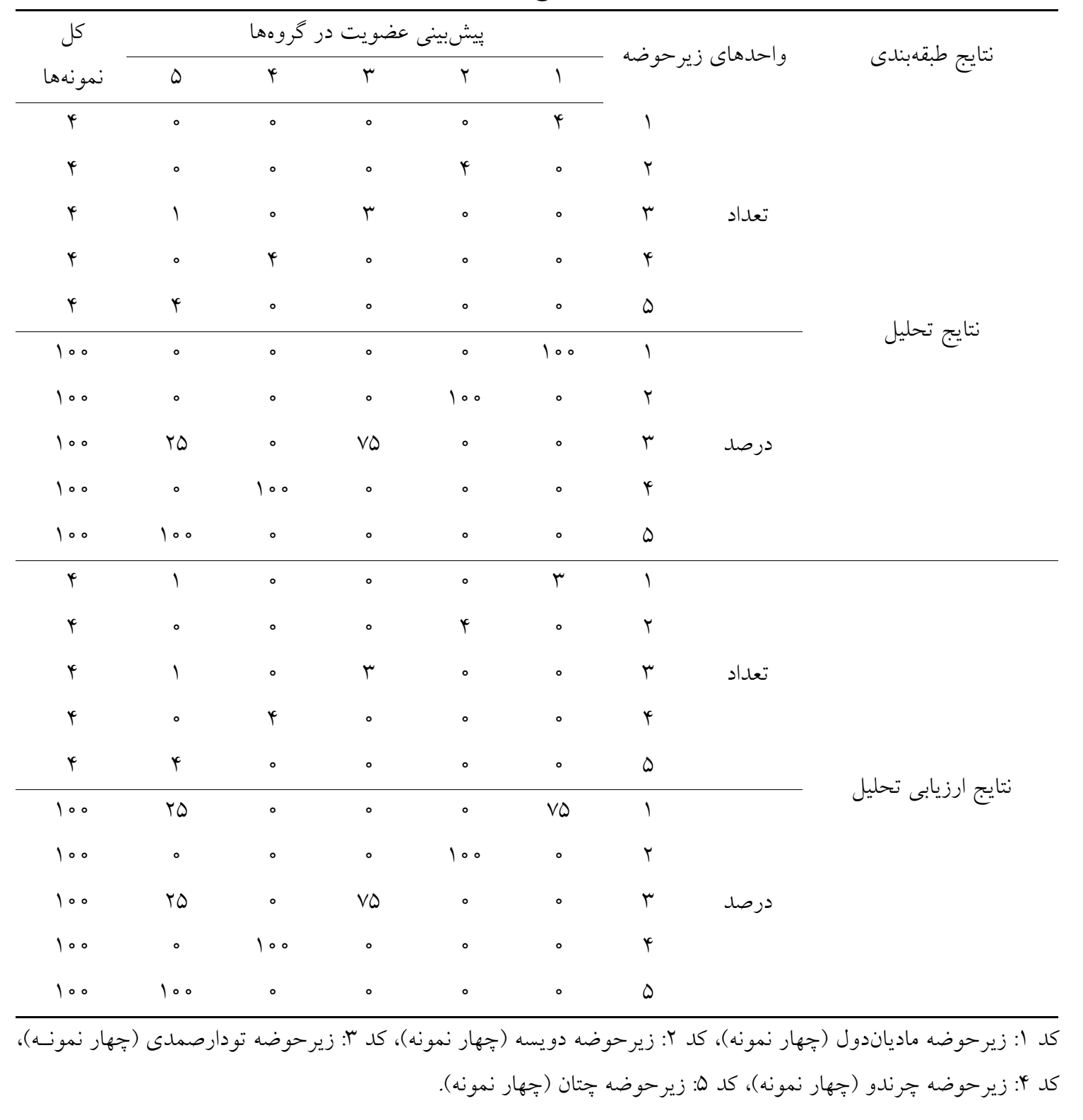

با توجه به نتايج بهدست آمله، ويزگگى هاى مغناطيسى رسـوبات بهدليل منـابع آبسى بيشـتر ايسن دو زيرحوضسه نسـبت بـه ديخـر بهخوبى توانستند منـابع رسـوب را از هـم تفكيـك كنــد. ايسن زيرحوضههاى منطقه است، همجنين ايسن دو زيرحوضـه داراى جداسازى حاكى از مغناطيسىشدن رسـوبات در حوضـه بـود و شيب تند (بيش از هr درصــ) هسـتند كـه از عوامـل مـؤثر در

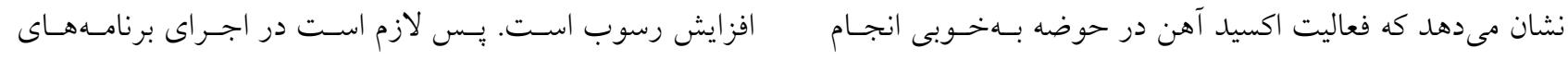

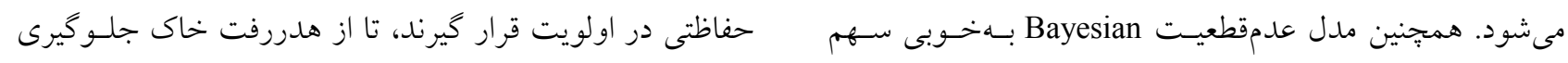

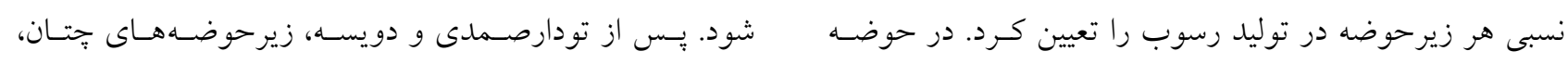

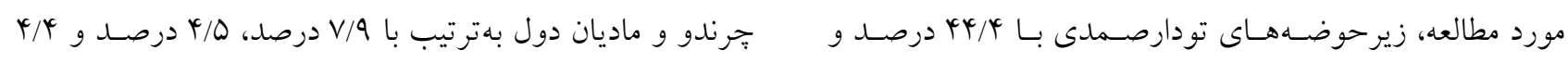
دويسه ه/هم درصد بيشترين رسوب منطقه را توليد مى كنند كـه درصد كمترين سهم را در توليد رسوب داشتند. زيرحوضه جتان 
تعيين سهم نسبى زيرحوضهها در توليد رسوب بهوسيله دادهاى بذيرفتتارى مغناطيسى

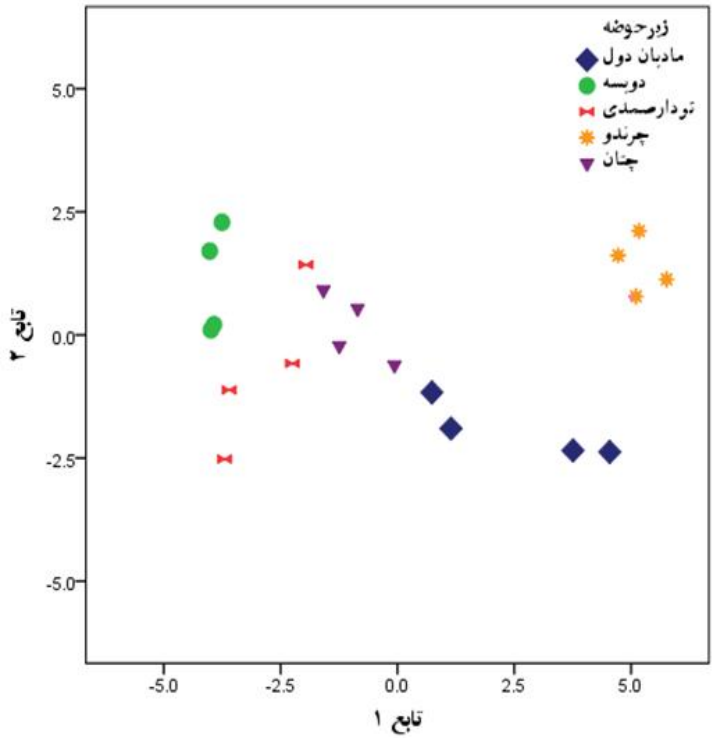

شكل r. نمودار براكنش تابع ا و Y تحليل تشخيص براساس تركيب بهينه ردياب بذيرفتارى مغناطيسى رسوب

جدول ه. نتايج سهم نسبى رسوبات در واحدهاى زيرحوضه

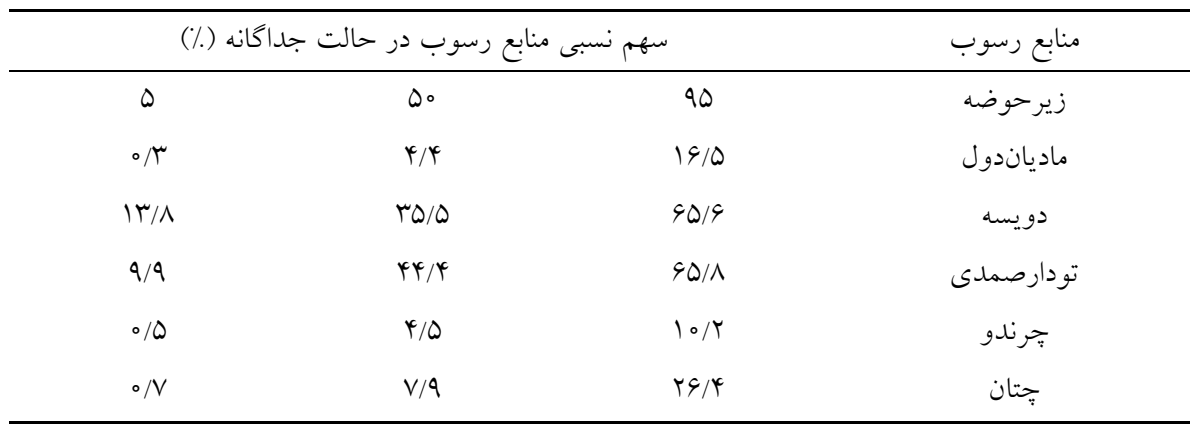
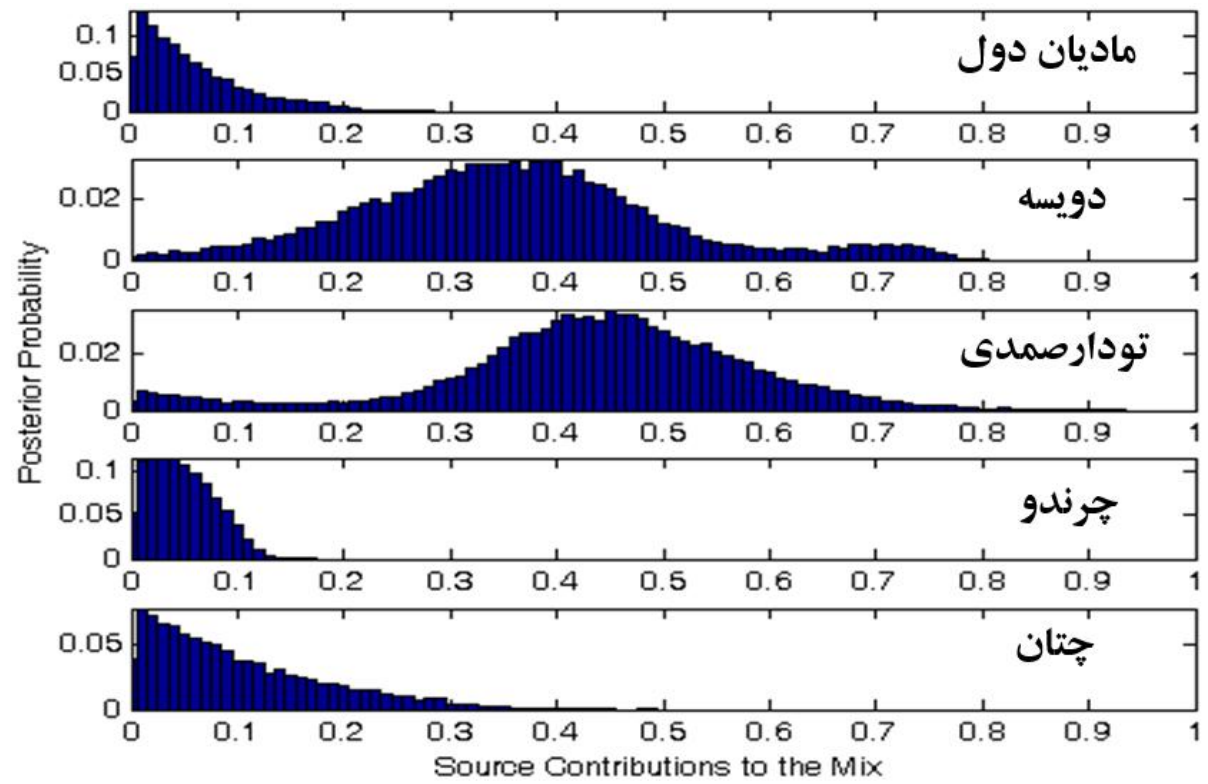

شكل f. سهم نسبى توليد بهصورت تركيبى با استفاده از مدل عدم قطعيت Bayesian در واحدهاى زيرحوضه

$r 90$ 


$$
\begin{aligned}
& \text { (19/00 درصد مساحت منطقه) در منطقه يـايينى داراى شـرايط (Y) سهم نسبى توليد رسوب بهصورت تركيبى با استفاده از مدل } \\
& \text { دو حوضه قبل بود و البته بهدليل نزديكسى بـه خروجسى حوضـه عدمقطعيت Bayesian نشان داده شده است. }
\end{aligned}
$$

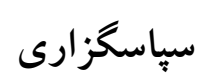

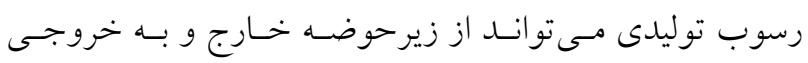

$$
\begin{aligned}
& \text { حوضه برسد. در زيرحوضه ماديان دول (r// rq درصد مساحت } \\
& \text { منطقه) بهدليل منابع آبى كـم و مسـاحت زيـاد، ايسن يسيشبينى فيش }
\end{aligned}
$$

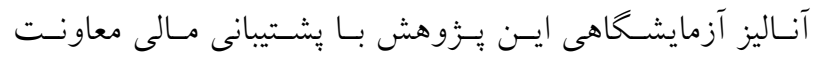

$$
\begin{aligned}
& \text { مىشود كه بيشتر رسوب توليـدى در درون زيرحوضسه بـه تلـه }
\end{aligned}
$$

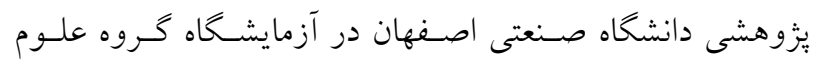

$$
\begin{aligned}
& \text { خاك دانشخاه صنعتى اصفهان انجام شده است كه بدينوسيله از } \\
& \text { اين معاونت تشكر و قدردانى مىشود. } \\
& \text { افتاده و بـه خروجسى حوضسه نمسىرسـد. همجنسين زيرحوضسه }
\end{aligned}
$$

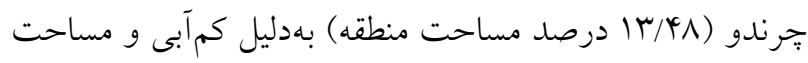

$$
\begin{aligned}
& \text { كم داراى كمترين سهم در توليد رسوب حوضه است. در شكل }
\end{aligned}
$$

\section{منابع مورد استفاده}

1. Ahmadi Mirghaed, F., B. Suri and M. Pirbavaghar. 2013. Evaluation of land environmental capacity for rangeland functional development (case study: parcel a of qesh watershed). Rangeland and Watershed Journal 3: 321 -334 (In Farsi).

2. Blake, W. H., P. J. Wallbrink, S. H. Doerr, R. A. Shakesby and G. S. Humphreys. 2006. Magnetic enhancement in wildfire-affected soil and its potential for sediment-sources ascription. Earth Surface Process Land 31: 249-264.

3. Booth, C. A., M. A. Fullen, J. Walden, J. P. Smith, M. D. Hallett, J. Harris and K. Holland. 2005. Magnetic properties of agricultural topsoils of the isle of man: their characterization and classification by factor analysis. Communication Soil Science Plant 36: 1241-1262.

4. Carter, J., P. N. Owens, D. E. Walling and G. J. L. Leeks. 2003. Fingerprinting suspended sediment sources in a large urban river system. Science Total Environment 314-316: 513-534.

5. Choundhary, M. A., A. R. Lal and W. A. Dick. 1997. Long-term tillage effect on run off and soil erosion under simulated rainfall for a Central Ohio soil. Soil Tillage Resarch 42: 175-184.

6. Collins, A. L. and D. E. Walling. 2006. Investigation of the remobilization of fine sediment stored on the channel bed of lowland permeable catchments in the UK. Pp.471-479. In: Sediment dynamics and the hydromorphology of the fluvial system. International Association of Hydrological Sciences Publication No. 306, Wallingford, UK.

7. Collins, A. L., Y. Zhang, R. Hickinbotham, G. Bailey, S. Darlington and S. E. Grenfell. 2013. Contemporary finegained bed sediment sources across the river Wensum Demonstration Test Catchment, UK. Hydrological Process 27: 857-884.

8. Dearing, J. A. 1994. Booklet - Environmental Magnetic Susceptibility - Using the Bartington MS2 System.

9. Devereux, O. H., K. L. Prestegaard, B. A. Needelman and A. C. Gellis. 2010. Suspended-sediment sources in an urban watershed, Northeast Branch Anacostia River, Maryland. Hydrolological Process 24: 1391-1403.

10. FAO, UNDP. 1994. Land degradation in South Asia: its severity causes and effects upon the people. World Soil Resources Reports No. 78.

11. Fathabadi, A., A. Salajegheh, H. Pezeshk, A. Nazari Samani and H. Rouhani. 2017. Soil eorison in north of Iran by fingerprinting. Iranian Natural Resources Journal 70: 57-69. (In Farsi).

12. Foster, I. D. L., J. Boardman and J. Keay-Bright. 2007. Sediment Tracing and Environmental History for Two Small Catchments, Karoo Uplands, South Africa.

13. Haddadchi, A., K. Nosrati and F. Ahmadi. 2014. Differences between the source contribution of bed material and suspended sediment in a mountainous agricultural catchment of Western Iran. Catena 116: 105-113.

14. Hakimkhani, S. 2010. Evaluation of the importance of different types of erosion in sediment production (case study: ghare aghaj basin, maku). Natural Resources Journal. 63: 13-27. (In Farsi).

15. Ingrid, F. S., S. R. John and W. F. Stewart. 2002. Quantitative sediment fingerprinting using a Bayesian uncertainty estimation framework, IAHS 276: 443-450.

16. Jalalian, A. 2011. Land degradation and its consequences in Iran. In: Proceeding of the $12^{\text {th }}$ Soil Congress, Tabriz University. Iran. (In Farsi).

17. Jalalian, A. 2011. Soil degradation and its effect in Iran. In: Proceeding of the Twelve Iran Soil Congress. Tabriz University, Iran. (In Farsi). 
18. Kouhpeyma, A., S. Feiznia, H. Ahmadi and M. Moazzami. 2011. Investigation of the effect of soil magnetic properties on separation of sediment sources. Physics and Spaces Journal 1: 11-19. (In Farsi).

19. Minella, J. P. G., D. E. Walling and G. H. Merten. 2008. Combining sediment source tracing techniques with traditional monitoring to assess the impact of improved land management on catchment sediment yields. Journal of Hydrology 348: 546-563.

20. Nosrati, K. 2011. Sediment source based on uncertainty estimation. Iranian Water Research Journal 9: 51-60. (In Farsi).

21. Nosrati, K., G. Govers, H. Ahmadi, F. Sharifi, M. A. Amoozegar, R. Merckx and M. Vanmaercke. 2011. An exploratory study on the use of enzyme activities as sediment traces: biochemical fingerprints? International Journal Sediment Resarch 26(2): 136-151.

22. Nosrati, K., G. Govers, X. Semmens and J. Ward. 2014. A mixing model to incorporate uncertainty in sediment fingerprinting. Geoderma 218: 173-180.

23. Nouria, A., E. H. Sayouty and M. Benmansour. 2003. Use of Cs-137 technique for soil erosion study in the agricultural region of Casablanca in Morocco. Jouranl of Environmnetal Radioctivity 68: 11-26.

24. Owens, P. N., W. H. Blake and E. L. Petticrew. 2006. Changes in sediment sources following wildfire in mountainous terrain: a paired-catchment approach, British Columbia, Canada. Water Air Soil Pollution: Focus 6: 637-645.

25. Poulenard, J., Y. Perrette, B. Fanget, P. Quetin, D. Trevisan and J. M. Dorioz. 2009. Infrared spectroscopy tracing of sediment sources in small rural watershed (French Alps). Science Total Environment 407: 2808-2819.

26. Singh, M. J. and K. L Khera. 2009. Physical indicators of soil quality in relation to soil erodibility under different land uses. Arid Land Resarch Management 23: 152-167.

27. Smith, J. 1999. An introduction to the magnetic properties of natural materials. In: Walden, J., F. Oldfield, J. P. Smith (Eds). Environmental Magnetism: A Practical Guide. Technical Guide, No 6. Quaternary Research Association, London.

28. SPSS, IBM. 2005. SPSS Base 14 user's guide, Prentice Hall.

29. Stutter, M. L., S. J. Langan, D. G. Lumsdon and L. M. Clark. 2009. Multi-Element signatures of stream sediments and sources under moderate to low flow conditions. Appled Geochemistry 24: 800-809.

30. Zokaee, M. 2005. Climate Environmental Plan: The Second Iranian State Environmental Report. First Edition. Iranian Environmental Protection Agency. (In Farsi). 


\title{
Determining the Relative Contribution of Sub-basins to Sediment Production by Magnetic Susceptibility Data
}

\author{
K. SeydiNaureh ${ }^{1}$, S. Ayoubi ${ }^{*}$ and K. Nosrati ${ }^{2}$
}

\begin{abstract}
The purpose of this study was to determine the relative contribution of sub-basin resources to sediment production by using magnetic susceptibility data as the tracer in Chehelgazi catchment, Sanandaj. For this purpose, 20 samples of the output 5 sub-basins were measured by harvesting and magnetic susceptibility. Kruskal-Wallis test results showed that in all three trackings, frequency high, low and dependent, at least two sources had the ability to differentiate. In the second step, the three tracers were tested on the discriminant analysis by the sub-basin source and two tracers with different power splitters showed the high frequency of $88 \%$ and the frequency dependence of $12 \%$; power splitters both tracers together in the sub-basin splitters was $90 \%$, so they were selected as the optimal combination; therefore, they have the capability to determine the relative contribution model of sediment. The results of Bayesian uncertainty model also indicated Todarsamadi sub-basin with $44.4 \%$ of the largest contribution and Doveyseh, Chatan and Cherendo subbasins with 35.5, 7.9 and 4.5, respectively, and Madian Dol sub-basin with 4/4 percent had the lowest contribution to sediment production. Based on the available results, Todarsamadi and Doveyseh sub-basins had the highest amount of sediment production; so these results could be used in soil conservation and management planning.
\end{abstract}

Keywords: Sediment fingerprinting, Magnetic susceptibility, Chehelgazi catchment, Bayesian uncertainty model

1. Department of Soil Science and Engineering, College of Agriculture, Isfahan University of Technology, Isfahan, Iran.

2. Department of Natural Geography, Faculty of Earth Sciences, Shahid Beheshti University, Tehran, Iran.

*: Corresponding Author, Email: ayoubi@cc.iut.ac.ir 